\title{
Groundwater sources and geochemical processes in a crystalline fault aquifer
}

Clément Roques (1), Luc Aquilina (1), Olivier Bour (1), Jean-Christophe Maréchal (2), Benoît Dewandel (2), Hélène Pauwels (3), Thierry Labasque (1), Virginie Vergnaud-Ayraud (1), and Rebecca Hochreutener (1)

(1) OSUR - Géosciences, University of Rennes 1 - CNRS, Av. Du Général Leclercq, 35042 Rennes, France , (2) BRGM, Water Dept., New Water Resource \& Economy Unit, 1039 rue de Pinville, 34000 Montpellier, France, (3) BRGM Water Dept., 3 av. Guillemin, BP 36009, 45060 Orléans Cedex 2, France

The functioning of aquifers related to fault-systems in crystalline rocks $(0-300 \mathrm{~m})$ is poorly known. The origin of water flowing in fractures or faults at great depth is particularly difficult to define. This work describes a field study designed to characterize the geochemical compartmentalization of an aquifer system constituted by a sub-vertical permeable fault-zone overlaid by a horizontal weathered domain. Analyses of the major chemical elements, trace elements, dissolved gases and isotopes revealed the origin of dissolved components for each aquifer domain and provided information on various water sources involved during different seasonal regimes. We also examined the geochemical response induced by performing a pumping test in the major fault-zone, in order to quantify mixing processes and contribution of different domains to the flow. We could also identify reactive processes enhanced by pumping and describe dynamic evolution of different geochemical reaction related to changes in hydrodynamic conditions.

The fault aquifer-domain presents different geochemical responses during seasonal hydraulic regime changes. They are interpreted as different water sources related to various porosity structures within the aquifer system. During the summer low water regime, results suggest mixing of recent water with a clear contribution of older water of inter-glacial origin (recharge temperature around $7^{\circ} \mathrm{C}$ ), suggesting the involvement of water trapped in a local low-permeability domain in the micro-fractures and/or pore-permeability. During winter, due to inversion of the hydraulic gradient between the fault and its surrounding domains, modern water predominantly flows down to the major fault-zone through local secondary fractures which ensure water supply.

In water abstraction context, the major fault-zone appears to be very dependent on connected storage-reservoirs. The overlaid weathered domain ensures around $20 \%$ of the flow rate. During late-time pumping, water stored within the damaged zone of the fault and graben structure ensures $80 \%$ of the flow rate. Different reactive processes are induced by mixing of water from different sources and transfer conditions. In particular, autotrophic denitrification coupled to iron minerals oxidation is observed and water rock interaction is clearly enhanced by the flux changes induced by pumping.

These results open up opportunities for studying the correlation between flux modifications and reactive transport on a large scale in groundwater abstraction context, with a view to better managing the quality of groundwater resources. 